\title{
TEORIA DOS CUSTOS DE TRANSAÇÃO: ANÁLISE BIBLIOMÉTRICA E SOCIOMÉTRICA DA LITERATURA CIENTÍFICA DE 1945 A 2018
}

\author{
iD Anderson Betti Frare ${ }^{1}$ (i) Vagner Horz $^{2}$ Carla Milena Gonçalves Fernandes ${ }^{3}$ (D) Débora Gomes de Gomes ${ }^{4}$ (D) \\ Marcos Antonio de Souza ${ }^{5}$
}

\author{
${ }^{1}$ Universidade Federal de Santa Catarina-UFSC. Florianópolis, Santa Catarina-Brasil.anderson_betti_frare@hotmail.com \\ ${ }^{2}$ Universidade Federal do Rio Grande - FURG. Rio Grande, Rio Grande do Sul-Brasil.vagnerhorz@ gmail.com \\ ${ }^{3}$ Universidade Federal do Rio Grande - FURG. Rio Grande, Rio Grande do Sul-Brasil. carlafernandes@furg.br \\ ${ }^{4}$ Universidade Federal do Rio Grande-FURG. Rio Grande, Rio Grande do Sul-Brasil. debora_furg@yahoo.com.br \\ ${ }^{5}$ Universidade Federal de Uberlândia - UFU. Uberlândia, Minas Gerais-Brasil.marcos.souzal@ufu.br
}

\section{Resumo}

Objetivo do estudo: Analisar as características das publicações científicas acerca da Teoria dos Custos de Transação (TCT).

Metodologia / abordagem: Para a seleção do portfólio analisado, utilizouse a base de dados Web of Science e alguns critérios para refinar a amostra, resultando em 9.907 artigos científicos. Com foco Bibliométrico e Sociométrico, os dados foram analisados por meio do package bibliometrix nos softwares R e RStudio.

Originalidade / Relevância: Há predominância de análises direcionadas a um único campo de pesquisa e eventos ou periódicos específicos, amostras compostas por quantidades medianas de publicações, bem como cortes temporais limitados de análise ou de circunscrita localização geográfica. Assim, o estudo proporciona um panorama global da literatura.

Principais resultados: Há um acentuado crescimento do número de publicações, principalmente a partir de 1990 . O periódico com maior número de publicações e mais referenciado é o Strategic Management Journal. Os autores com maior rede de colaboração são Wang, Y., com 41 publicações, e Zhang, Y., com 29. Dentre as obras mais citadas e redes de cocitação, destacam-se as produções de Williamson e Coase. Os Estados Unidos detêm o maior número de artigos em parceria com outros países, o que sinaliza a importância de outros países, em especial, o Brasil, buscar por parcerias científicas. Nas palavras-chave, custos, mercado, vantagem competitiva e desempenho tomam ênfase quando atreladas à temática custos de transação. Contribuições teóricas / metodológicas: A investigação contribui ao propiciar ampla visão do estado do conhecimento científico e apontar perspectivas futuras das publicações sobre TCT.

Palavras-chave: Teoria dos custos de transação. Custos de transação. Publicações científicas. Package bibliometrix.

\section{TRANSACTION COST THEORY: BIBLIOMETRIC AND SOCIOMETRIC ANALYSIS OF SCIENTIFIC LITERATURE FROM 1945 TO 2018}

Abstract

Objective: To analyze the characteristics of scientific publications about the Theory of Transaction Costs (TCT).

Methodology / approach: For selection of the analyzed portfolio, the Web of Science database and some criteria were used to refine the sample, resulting in 9,907 scientific articles. With a Bibliometric and Sociometric focus, the data were analyzed using the bibliometrix package in the $\mathrm{R}$ and RStudio software.

Originality / Relevance: There is a predominance of analyzes aimed at a single field of research and specific events or journals, samples composed of median quantities of publications, as well as limited time cuts in analysis or circumscribed geographic location. Thus, the study provides a global overview of the literature.

Results: There has been a marked increase in the number of publications, especially since 1990 . The journal with the highest number of publications and the most referenced is the Strategic Management Journal. The authors with the greatest collaboration networks are Wang, Y., with 41 publications, and Zhang, Y., with 29. Among the most cited works and co-citation networks, the productions of Williamson and Coase stand out. The United States has the largest number of articles in partnership with other countries, which signals the importance of other countries, in particular, Brazil, seeking scientific partnerships. Regarding keywords, there is an emphasis in costs, market, competitive advantage, and performance when linked to transaction costs.

Theoretical / methodological contributions: The research contributes by providing a broad view of the state of the art in scientific knowledge and pointing out future perspectives of publications on TCT.

Keywords: Transaction costs theory. Transaction costs. Scientific publications. Bibliometrix package.

\section{TEORÍA DEL COSTO DE TRANSACCIÓN: ANÁLISIS BIBLIOMÉTRICO Y SOCIOMÉTRICO DE LA LITERATURA CIENTÍFICA DE 1945 A 2018}

Resumen

Objetivo: Analizar las características de las publicaciones científicas sobre la Teoría de los Costos de Transacción (TCT).

Metodología / enfoque: Para la selección de la cartera analizada, se utilizó la base de datos Web of Science y algunos criterios para refinar la muestra, lo que resultó en 9,907 artículos científicos. Con un enfoque bibliométrico y sociométrico, los datos se analizaron utilizando el package bibliometrix, en el software R y RStudio.

Originalidad / Relevancia: Hay un predominio de los análisis dirigidos a un solo campo de investigación y eventos específicos o revistas, muestras compuestas de cantidades medianas de publicaciones, así como cortes de tiempo limitados en el análisis o ubicación geográfica circunscrita. Por lo tanto, el estudio proporciona una visión global de la literatura.

Resultados: Ha habido un marcado aumento en el número de publicaciones, especialmente desde 1990. La revista con más publicaciones y la más referenciada es la revista Strategic Management Journal. Los autores con las mayores redes de colaboración son Wang, Y., con 41 publicaciones, y Zhang, Y., con 29. Entre las obras más citadas y las redes de citas, destacan las producciones de Williamson y Coase. Estados Unidos tiene el mayor número de artículos en asociación con otros países, lo que indica la importancia de que otros países, en particular, Brasil busquen asociaciones científicas. En las palabras clave, los costos, el mercado, la ventaja competitiva y el rendimiento se enfatizan cuando se vinculan con los costos de transacción. Contribuciones teóricas / metodológicas: la investigación contribuye proporcionando una visión amplia del estado del conocimiento científico y señalando las perspectivas futuras de las publicaciones sobre TCT.

Palabras-clave: Teoría del Costo de Transacción. Costo de Transacción. Publicaciones cientificas. Package bibliometrix.

\section{Cite as / Como citar}

American Psychological Association (APA)

Frare, A. B., Horz, V., Fernandes, C. M. G., Gomes, D. G., \& Souza, M. A. (2020, July/Sept.). Teoria dos custos de transação: análise bibliométrica e sociométrica da literatura científica de 1945 a 2018. Iberoamerican Journal of Strategic Management (IJSM), 19(3), 67-89. https://doi.org/10.5585/riae.v19i3.16431 


\section{Introdução}

O surgimento da discussão acerca da Teoria dos Custos de Transação (TCT) teve origem no trabalho de Coase (1937). No entanto, foi apenas em meados dos anos 1970 que a TCT passou por um aprimoramento de suas premissas, bem como se observou um crescente estágio de desenvolvimento (Williamson, 1998). Os custos de transação caracterizam-se por contemplarem toda e qualquer operação presente em um sistema econômico (North, 1990), abrangendo os custos necessários para desenvolverse a transação, ou seja, todo o gasto decorrente da efetivação da transferência de determinado bem (Coase, 1937).

A firma é a entidade definida pelos custos de transação, visto que nela não existe nenhuma transferência de bens que não gere custos, seja na busca, especulação, negociação, ou realização efetiva da operação (Coase, 1937). Dentro desses estágios da operação, Williamson (1981) definiu transações como atividades decorrentes da existência de partes e na forma em que essas atividades estariam delimitadas dentro dos níveis organizacionais.

Em algumas literaturas organizacionais, como naquelas relacionadas a alianças estratégicas (Ferreira, Storopoli \& Serra, 2014), reestruturação do portfólio de negócios (Sánchez-Riofrío, GuerrasMartín \& Forcadell, 2015), internacionalização (Bužavaitė, Ščeulovs \& Korsakienė, 2019), interface entre a internacionalização e grupos de negócios (Aguilera, Crespí-Cladera, Infantes \& Pascual-Fuster, 2020) e, de forma ampla, o contexto de gestão e negócios (Martins, Serra, Leite, Ferreira \& Li, 2010), a TCT é uma das fundamentações utilizadas com frequência. Nesta perspectiva, levando-se em conta a pertinência da TCT, alguns pesquisadores realizaram estudos do estado da arte das pesquisas sobre esse tema.

Arruda et al. (2013) realizaram uma análise bibliométrica e sociométrica acerca da TCT de 1997 a 2010, presente nos anais dos congressos do Encontro Nacional dos Programas de Pós-Graduação em Administração (ENANPAD). Ferreira, Pinto e Serra (2014) desenvolveram estudo semelhante, tomando como base nove revistas conceituadas na área de negócios, abrangendo o período de 1982 a 2010.

Ampliando o campo de pesquisa, Peixe et al. (2016) desenvolveram um estudo bibliométrico sobre os custos de transação aplicados aos setores público e privado de 2005 a 2015, conforme amostra composta pelos artigos dos anais do Congresso Brasileiro de Custos e do International Conference in Accounting, da Universidade de São Paulo (USP). De forma semelhante, Foscaches e Saes (2017) estudaram bibliometricamente a economia dos Custos de Transação e a Teoria da Identidade, utilizando o Scopus como base de dados.

Sob a ótica da área da estratégia, Andrade, Barbosa e Santos (2015), Maranho, Abib e Fonseca (2013) e Santos, Ferraz, Falqueto e Verga (2017) promoveram investigações das pesquisas da TCT neste campo. Não obstante, Bezerra, Schultz, Schinaider e Schinaider (2017) conduziram uma revisão da literatura dos Custos de Transação no agronegócio, mediante publicações presentes no Scopus. Deste 
modo, a TCT pode ser compreendida como uma teoria que abarca ampla gama de estudos na área de gestão e negócios (Martins et al., 2010).

Por meio da análise dos estudos supracitados, notou-se a predominância de análises direcionadas a um único campo de pesquisa e eventos ou periódicos específicos. Ademais, observou-se amostras compostas por quantidades restritas de publicações, assim como cortes temporais limitados de análise ou de circunscrita localização geográfica. Neste ínterim, com o propósito de preencher, ainda que parcialmente, as lacunas de pesquisas pregressas, propôs-se a seguinte questão de pesquisa: Qual o perfil das publicações relacionadas à Teoria dos Custos de Transação nas últimas sete décadas? Consoante à questão de pesquisa, tem-se o objetivo de analisar as características das publicações científicas que se relacionem à Teoria dos Custos de Transação, com uma maior delimitação de corte temporal, geográfico ou por área do conhecimento, usando para isso a base de dados Web of Science.

A justificativa para tal pesquisa se embasa no complemento aos estudos citados, uma vez que se acrescenta e se altera as variáveis de análise. Por ser uma teoria amplamente abordada em pesquisas no contexto das firmas, englobando conhecimentos de gestão com vieses administrativos, econômicos e contábeis (Foscaches \& Saes, 2017), torna-se pertinente apresentar o perfil das publicações para compreender os momentos e o estado da arte de desenvolvimento do tema (Ferreira et al., 2014). Estudos de caráter bibliométrico tendem a evidenciar correntes e tendências acerca dos temas de interesse, o que permite aos pesquisadores a identificação dos eixos centrais na discussão sobre o assunto (Serra, Ferreira, Guerrazzi \& Scaciotta, 2018).

Esta pesquisa espera contribuir para a teoria ao evidenciar um amplo panorama histórico das características das publicações, de forma a abarcar aspectos relacionados a evolução, tendências e estado da arte. Para o meio acadêmico, especialmente para pesquisadores interessados na temática abordada, o estudo serve como base para conhecimento dos principais autores, artigos científicos, periódicos, países prolíferos, redes de coautoria, dentre outros aspectos. Consonante ao rol de possíveis contribuições para a prática, espera-se elucidar e instigar entrelaços da teoria com fenômenos das organizações que os gestores podem se deparar, e, a partir do conhecimento teórico da TCT, encontrar subsídios para compreender e gerenciar o contexto.

O estudo estrutura-se em cinco seções. A primeira seção abarca aspectos introdutórios, para alcançar a revisão da literatura sobre TCT, situada na segunda seção. Na sequência, detalha-se os procedimentos metodológicos adotados. Na quarta seção apresenta-se e discute-se os dados obtidos. Por fim, tem-se a seção que contempla as considerações finais.

\section{Teoria dos Custos de Transação}

A Teoria dos Custos de Transação surgiu com as contribuições de Coase (1937), com o objetivo de agregar elementos institucionais da estrutura de economia capitalista à teoria econômica clássica (Sarto \& Almeida, 2015). Na visão de Arrow (1969), os custos de transação podem ser definidos como 
aqueles necessários para a continuidade do sistema econômico. Deste modo, Thielman (2013) destaca a existência de duas vertentes comportamentais que constituem os custos de transação: (1) racionalidade limitada (dificuldade do comportamento humano em explorar todos os elementos inseridos em uma transação); e (2) oportunismo, uma condição de interesse próprio (Williamson, 1998).

Além disso, o conceito de custos de transação tem como base dois eixos distintos, mas complementares: (1) distribuição dos direitos de propriedade; e (2) natureza da produção e sua eficiência de equilíbrio. Com relação ao primeiro, fazem parte as diretrizes que guiam o comportamento das organizações, tais como as leis, regras e os costumes sociais. No que tange ao segundo eixo, encontrase um caminho para um novo aparato econômico institucional, baseado pela economia neoclássica (Allen, 1999).

Neste ínterim, inserido nos eixos da TCT encontram-se duas dimensões, que também fazem parte de perspectivas econômicas para/entre as organizações, sendo elas: Teoria dos Custos de Mensuração (TCM) e a Visão Baseada em Recursos (VBR). Com relação a TCM, seu objetivo consiste na redução dos custos de transação (Barzel, 2002), particularmente nas relações entre os direitos de propriedade e as formas de mensuração de tais custos (Zylbersztajn, 2018). Em contrapartida, a VBR tem seu foco na eficiência das organizações, mais especificamente quando ao uso dos recursos estratégicos, desde a parte física que constitui a empresa às partes interessadas contratadas para nela atuarem (Kellermanns, Walter, Crook, Kemmerer \& Narayanan, 2018; Santos et al., 2017).

Sendo assim, descreve-se o universo contratual como um mundo de planejamento, promessa, competência e governança. Considerar quais destas descrições são as mais aplicáveis é algo que depende dos pressupostos comportamentais aplicáveis, relevando a troca dos atributos econômicos do bem ou serviço em questão. Ademais, a harmonização da fase contratual, que une as partes para efetuar a adaptabilidade e promover a continuidade, converte-se em uma fonte de valor econômico real (Wiliamson, 1994).

Cabe às instituições econômicas a promoção de discussões que envolvam os custos de transação, pois, caso as implicações e perspectivas econômicas entre as organizações não sejam debatidas, não haverá sentido a existência de tais instituições (Fox, 2007). Por conseguinte, apesar do termo "custo de transação" ser originalmente cunhado por Coase, foi por meio das investigações de Williamson, na década de 1970, que foi possível repensar a teoria, tornando-a preditiva. Isso ocorreu a partir da caracterização das empresas, a partir de suas transações singulares, em função das especificidades dos ativos que as compõem (Madhok, 1998).

No contexto da TCT, está implícito a necessidade de distinguir os custos de transação em dos tipos: ex ante e ex post. O primeiro tipo (ex ante), materializados antes da realização efetiva da operação, refere-se aos custos de negociação. Estes devem ser analisados com cautela, assim como suas cláusulas contratuais devem estar claramente definidas pelas partes - lembrando que nenhum contrato é "perfeito", ou seja, abarcará todas possibilidades que podem acontecer em uma transação. Quanto ao segundo tipo (ex post), esse refere-se à manutenção de um acordo, como, por exemplo, a ocorrência de 
custos incorridos por falta de alinhamento ao contratado; custos de barganha incorridos para corrigir distorções após o acordo; custos de configuração, assim como o funcionamento das estruturas de governança para solucionar possíveis disputas (Wiliamson, 1994).

Em relação aos possíveis fatores determinantes para os custos de transação, aspectos como a propriedade e o contratante (ex ante), bem como o ambiente da transação e a eficiência da gestão dos projetos (ex post) podem ser cruciais (Li, Arditi \& Wang, 2015). O grau de fatores contextuais, como a qualidade da informação, incerteza do projeto, confiança, eficiência organizacional e requisições de mudanças também podem ser as causas dos custos de transação (Haaskjold, Andersen, Lædre \& Aarseth, 2019).

Os custos de transação podem surgir em quatro momentos distintos das relações contratuais: na criação do contrato, no controle, no desempenho e na conclusão. O monitoramento dos contratos que busca mitigar a assimetria da informação também gera custos de transação, como, por exemplo, para verificar o comportamento do agente ex post a contratação ou a busca de informações ex ante do início da relação contratual (Martinez, 1998).

Evidenciando-se a pertinência da TCT, desde sua origem até a contemporaneidade (Rindfleisch, 2020), pesquisas foram desenvolvidas com o objetivo de revisar as diferentes literaturas sobre o assunto. Na pesquisa de Arruda et al. (2013) foi analisado o desenvolvimento da TCT, bem como a estrutura de relacionamento entre os pesquisadores que trabalharam com a teoria nos ENANPADs, especificamente no período de 1997 a 2010. Os resultados demonstraram que as áreas de Estratégia em Organizações (ESO) e Gestão de Operações e Logística (GOL) foram as que mais abordaram a TCT como fundamentação central em seus artigos. Os autores perceberam ainda a falta de laços entre as redes dos autores mais prolíficos e entre os autores de modo geral (Arruda et al., 2013).

Ferreira et al. (2014) examinaram até que ponto a TCT é usada e impacta pesquisas sobre a perspectiva de International Business (IB). Os achados demonstraram que a TCT está expressivamente presente no IB ao longo das últimas três décadas, especificamente aos estudos relacionados à VBR, de forma a percorrer as suas variantes fundamentadas em capacidades e conhecimentos.

No estudo de Peixe et al. (2016) foram analisados de forma bibliométrica os custos de transação aplicados aos setores público e privado, tendo como objeto de análise artigos dos anais do Congresso Brasileiro de Custos e a USP International Conference in Accounting, no período 2005 a 2015. Os resultados mostraram que, entre as principais áreas temáticas de publicações, cinco são relacionadas à área pública e 22 ao setor privado. As características de autoria explicitaram que os pesquisadores estavam atuando em equipes e/ou grupos de pesquisas menores, compostos de dois a quatro autores (Peixe et al., 2016).

Na pesquisa de Foscaches e Saes (2017) foi analisada de que forma a TCT e a Teoria da Identidade estão relacionadas, buscando verificar a existência de uma convergência entre elas. Os autores evidenciaram a presença de autores em comum nas áreas de TCT e da Teoria da Identidade. Bezerra et al. (2017) realizaram um estudo com foco em publicações internacionais focando os custos 
de transação para o segmento do agronegócio. Os achados apontaram que as publicações tiveram início em 2005, com dois artigos publicados. Dentre as principais culturas evidenciadas, os autores constataram a cultura da soja como a mais enfatizada, seguida pela cultura da cana-de-açúcar.

\section{Procedimentos metodológicos}

A pesquisa é de cunho descritivo, pois visa identificar e apresentar as características referentes a produção científica sobre a TCT. Para a resolução do problema de pesquisa empregou-se procedimentos metodológicos de viés quantitativo, dado que se aplicam análises e comparações baseadas em dados mensurados com aplicação de técnicas estatísticas (Martins \& Theóphilo, 2009).

O delineamento do portfólio de documentos transcorreu com base nos seguintes procedimentos: (1) utilização da base de dados Web of Science; (2) seleção de termos no título, resumo ou palavraschave: "transaction cost", "transactions costs", "transaction costs", "transactions cost", "transaction cost economics", "transaction cost theory", "transaction costs economics", "transaction costs theory", "transactions costs economics", "transactions costs theory"; (3) o intervalo temporal delimitado conforme disponibilizado pela base de dados, de 1945 a 2018 - 2019, não foi inserido, pois visou-se contemplar unicamente os ciclos anuais completos; e (4) sobre os tipos de documento, selecionou-se exclusivamente artigos científicos publicados em periódicos revisados por blind review.

Na aplicação do segundo critério, ressalta-se a utilização do operador de frase exata - aspas (“") - para cada termo mencionado, uma vez que retorna precisamente a expressão desejada na ordem literal dos termos dispostos. Como forma de promover a busca de pelo menos um dos termos citados no título, resumo ou palavras-chave dos documentos, utilizou-se o operador booleano - OR (ou) -, visto que este promove a união entre os termos chave, tornando-se útil na busca por sinônimos ou expressões similares (Colepicolo, 2014).

A etapa de seleção da amostra foi finalizada no início de junho de 2019; contemplando publicações realizadas até 2018, chegou-se a 9.907 artigos. Após o download das informações resultantes destes artigos em formato bibtex, as mesmas posteriormente foram importadas no package bibliometrix nos softwares R e RStudio. Tal package permite o tratamento de grandes quantidades de dados (big data) relativas à produção científica, facilitando a análise das variáveis a serem observadas (Aria \& Cuccurullo, 2017). A partir dos outputs gerados pelo bibliometrix, foram selecionadas para análise as seguintes variáveis: (1) evolução temporal; (2) periódicos; (3) autores; (4) citações; (5) países; (6) palavras-chave; (7) redes de colaboração; e (8) redes de cocitação.

As análises podem ser expressas sob duas óticas: bibliométrica e sociométrica. Para a análise bibliométrica utilizou-se a análise de conteúdo temática (Bardin, 2016), no intento de identificar aspectos centrais e de interesse para o portfólio de artigos. Na análise sociométrica foi realizada a identificação das redes de autores e instituições, bem como o cálculo dos indicadores de densidade (Otte \& Rousseau, 2002). 


\section{Apresentação e Discussão dos Dados}

Ao iniciar a discussão dos achados, a partir da Figura 1 infere-se uma constante evolução temporal dos artigos sobre TCT. Contudo, percebe-se uma acentuada expansão na quantidade de publicações a partir da década de 1990, com o auge no ano de 2018 (813 artigos).

Figura 1 - Produção científica annual

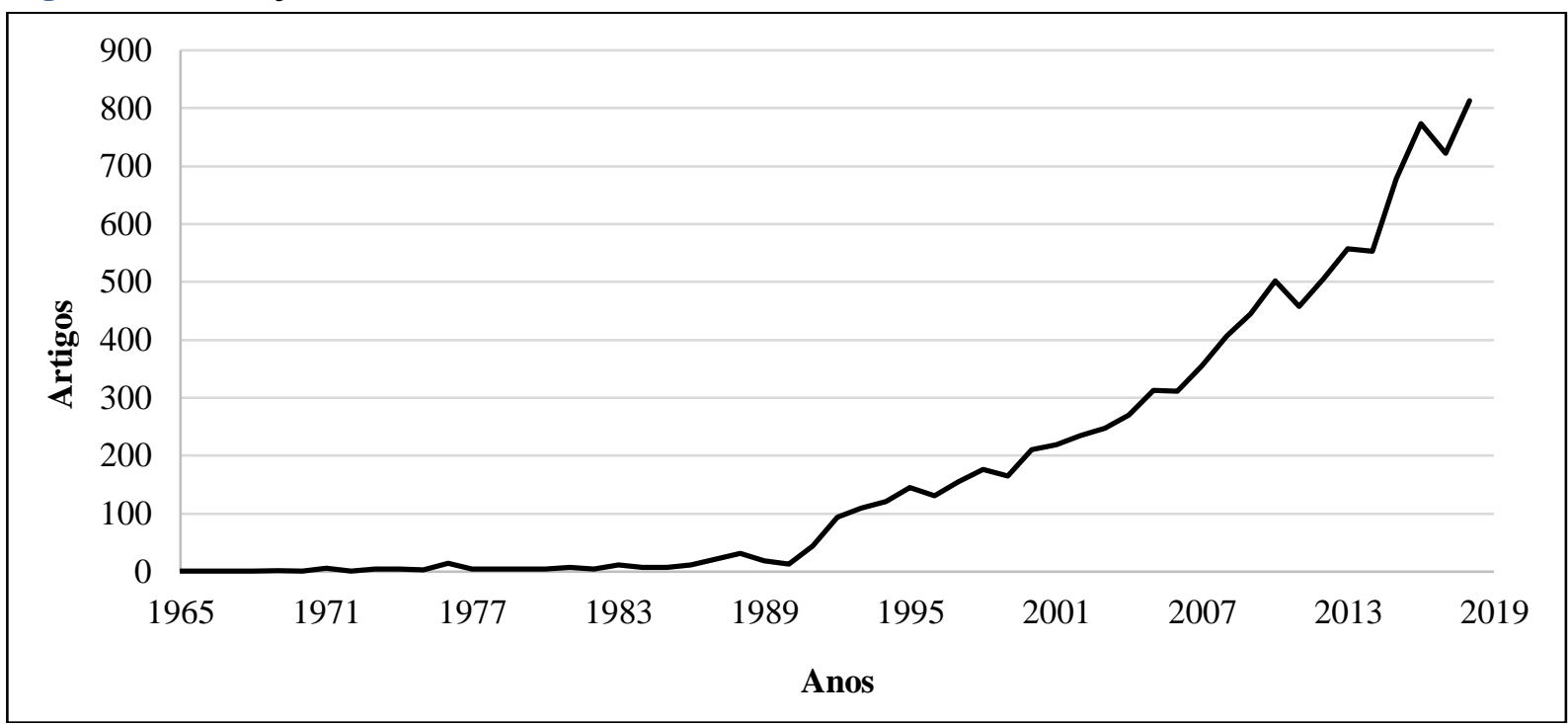

Fonte: Elaborado pelos autores com base nos dados da pesquisa.

Essa evidência da constante evolução nas publicações corrobora com o observado no Brasil por Arruda et al. (2013). Os autores em questão observaram tal crescimento nas publicações por meio da análise de anais do ENANPAD. Por sua vez, no Congresso Brasileiro de Custos e no USP International Conference in Accounting, compreendendo o período de 2005 a 2015, foi encontrada pouca diferença na quantidade de artigos apresentada nesse período (Peixe et al., 2016).

A análise sobre a proficuidade dos periódicos (Tabela 1) identificou 1.967 diferentes Journals. Na Tabela 1 são apresentados os 10 periódicos com maior número de artigos publicados sobre TCT, assim como os 10 periódicos mais referenciados dentre os journals que compõe a amostra. 
Tabela 1 - Principais periódicos

\begin{tabular}{l|c|l|c}
\multicolumn{1}{c|}{ Publicações } & Artigos & \multicolumn{2}{c}{ Referências } \\
\hline \multicolumn{1}{c|}{ Periódicos } & 125 & Strategic Management Journal & 13.699 \\
\hline Strategic Management Journal & 116 & Journal of Finance & 10.677 \\
\hline Journal of International Business Studies & 111 & Journal of International Business Studies & 8.731 \\
\hline Journal of Banking \& Finance & 96 & Journal of Financial Economics & 6.762 \\
\hline $\begin{array}{l}\text { Journal of Economic Behavior \& } \\
\text { Organization }\end{array}$ & 85 & Academy of Management Review & 6.089 \\
\hline Journal of Business Research & 84 & American Economic Review & 5.990 \\
\hline Organization Science & 78 & Academy of Management Journal & 5.811 \\
\hline Journal of Financial Economics & 77 & Journal of Marketing & 5.448 \\
\hline Quantitative Finance & 75 & Organization Science & 4.833 \\
\hline Journal of Finance & 73 & Management Science & 4.464 \\
\hline Management Science & & & \\
\hline
\end{tabular}

Fonte: Elaborado pelos autores com base nos dados da pesquisa.

O Strategic Management Journal apresenta-se como o periódico com maior quantidade de artigos na amostra, totalizando 125. O mesmo journal aparece como o mais citado dentre as referências utilizadas pelos documentos da amostra. Tais fatos realçam a pertinência do periódico na temática envolvendo a TCT, o que já havia sido pontuado por Ferreira et al. (2014). Este achado corrobora com Ramos-Rodríguez e Ruíz-Navarro (2004), no qual muitos dos estudos publicados na Strategic Management Journal se fundamentam ou contemplam a discussão da TCT.

Outro periódico que ganha destaque é o Journal of Finance, por aparecer na nona posição em quantidade de artigos e na segunda no quesito referências. Este achado mostra que mesmo não possuindo a maior quantidade de artigos sobre TCT, existe grande repercussão dos estudos publicados pelo periódico a respeito do tema. Fato semelhante ocorre com os periódicos Academy of Management Review, American Economic Review, Academy of Management Journal e Journal of Marketing, os quais encontram-se na perspectiva de mais referenciados, porém não estão entre os 10 que apresentam mais artigos publicados sobre a TCT.

No terceiro estágio das análises buscou-se verificar os aspectos relacionados aos autores e autorias. Evidenciou-se 15.401 diferentes autores, os quais apareceram 22.230 vezes, dado que alguns deles possuem autoria de mais de um artigo. Desta forma, denota-se uma média de 1,55 autores por documento, bem como 0,64 documentos por autor. Nesta perspectiva, conforme dados da Tabela 2, observa-se os autores mais profícuos e o número de artigos fracionados (número de autores por documento dividido pelo número de coautores), uma métrica adotada por Aria e Cuccurullo (2017). 
Tabela 2 - Principais autores

\begin{tabular}{c|c|c|c}
\hline \multicolumn{2}{|c|}{ Proficuidade } & \multicolumn{2}{c}{ Fracionalização } \\
\hline Autores & Artigos & Autores & Artigos \\
\hline Wang Y. & 41 & Williamson O. E. & 22 \\
\hline Zhang Y. & 29 & Wang Y. & 15,6333 \\
\hline Reuer J. J. & 24 & Hennart J. F. & 12,8333 \\
\hline Wang S. & 24 & Reuer J. J. & 11,25 \\
\hline Zhang X. & 23 & Wang S. & 11,2333 \\
\hline Williamson O. E. & 22 & Zhang Y. & 9,2167 \\
\hline Muhle Karbe J. & 21 & Brouthers K. D. & 9,0833 \\
\hline Zhang W. G. & 21 & Bouchard B. & 9 \\
\hline Chen Y. & 20 & Nooteboom B. & 9 \\
\hline Li X. & 20 & Menard C. & 8,6667 \\
\hline
\end{tabular}

Fonte: Elaborado pelos autores com base nos dados da pesquisa.

O autor com maior número de publicações é Wang Y, com o total de 41 artigos. No entanto, pela questão dos artigos fracionados, destaca-se Williamson. Pode-se inferir que este autor, em todas suas 22 publicações, foi o autor único, ou seja, não houve coautores em seus trabalhos. Além de ser um dos pioneiros da TCT, o fato de produzir isoladamente pode ter enaltecido o seu status nesta área de conhecimento (Sarto \& Almeida, 2015).

No campo da gestão estratégica, o legado de Williamson figura de forma importante pelas suas contribuições no âmbito da TCT (Nerur, Rasheed \& Natarajan, 2008). Tamanha consideração por Williamson resultou na obtenção do prêmio Nobel de Economia de 2009, por suas contribuições na construção e desenvolvimento da TCT (Earl \& Potts, 2011). Contudo, Williamson reconhece a influência de Coase (1937) em seus trabalhos e sua perspectiva teórica (Habimana, 2015).

Complementarmente às análises sobre autoria, tracejou-se uma análise temporal dos autores mais profícuos. Na Figura 2 expõe-se a trajetória dos anos que tais autores se dedicaram à produção científica sobre o tema, observando a quantidade de publicações para cada ano. 
Figura 2 - Principais autores ao longo do tempo

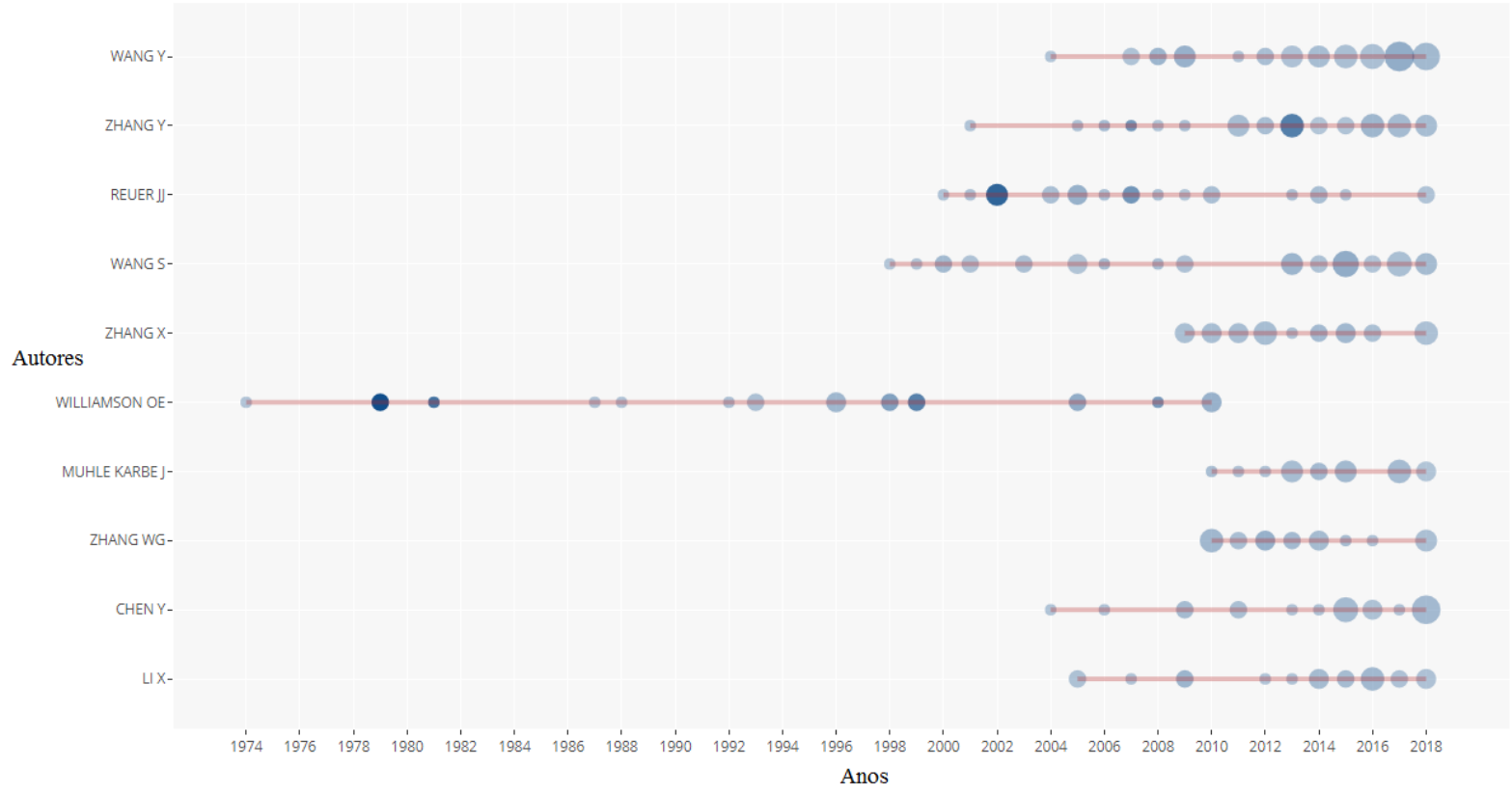

Fonte: Elaborado pelos autores com base nos dados da pesquisa tratados no package bibliometrix.

Os dados da Figura 2 reforçam o pioneirismo de Williamson dentre os principais autores, cuja predominância se estendeu por 36 anos. Percebe-se que no final do século passado e início deste, além da alavancagem na produção (Figura 1), alguns autores dedicaram-se fortemente a TCT. Nota-se nesse respeito que nos últimos anos os autores Wang Y., Zhang Y., Wang S., Chen Y. e Li X. apresentam considerável quantidade de publicações.

No intuito de averiguar os principais artigos (Tabela 3), foram observadas as referências mais citadas dentre o portfólio da amostra. De forma geral, constatou-se que os autores pioneiros possuem as obras mais citadas, sendo que, dos principais documentos, quatro são de Williamson, dois de Coase, além de autorias de Barney J., Dyer, J. H. e Singh, H. e North D. C., com um cada. 
Tabela 3 - Principais referências

\begin{tabular}{l|c}
\hline \multicolumn{1}{c}{ Documentos } & Citações \\
\hline Williamson O. E. (1985). The Economic Institutions of Capitalism. New York: Free Press. & 11.380 \\
\hline $\begin{array}{l}\text { Williamson O. E. (1975). Markets and Hierarchies: Analysis and Antitrust Implications: A Study } \\
\text { in the Economics of Internal Organization. New York: Free Press. }\end{array}$ & 10.280 \\
\hline Coase, R. H. (1937). The nature of the firm. Economica, 4(16), 386-405. & 10.070 \\
\hline $\begin{array}{l}\text { Williamson O. E. (1991). Comparative Economic Organization: The Analysis of Discrete } \\
\text { Structural Alternatives. Administrative Science Quarterly, 36(2), 269-296. }\end{array}$ & 6.080 \\
\hline $\begin{array}{l}\text { Williamson O. E. (1979). Transaction-Cost Economics: The Governance of Contractual Relations. } \\
\text { The Journal of Law and Economics, 22(2), 233-261. }\end{array}$ & 5.390 \\
\hline Barney, J. (1991). Firm resources and sustained competitive advantage. Journal of management, & 5.060 \\
17(1), 99-120. & 4.400 \\
\hline $\begin{array}{l}\text { Dyer, J. H., \& Singh, H. (1998). The relational view: Cooperative strategy and sources of } \\
\text { interorganizational competitive advantage. Academy of management review, 23(4), 660-679. }\end{array}$ & 4.210 \\
\hline North, D. C. (1994). Economic performance through time. The American economic review, 84(3), & 4.310 \\
\hline Coase R. H. (1960). The problem of Social Cost. The Journal of Law and Economics, 3(oct), 1-44. & \\
\hline
\end{tabular}

Fonte: Elaborado pelos autores com base nos dados da pesquisa.

Esses trabalhos, que são os mais citados na TCT, são corroborados com os achados de Foscaches e Saes (2017) e Santos et al. (2017), os quais evidenciaram as obras de Williamson e Coase adentre o topo das principais referências. Ademais, as quatro obras de Williamson mencionadas na Tabela 3 contemplam mais de 33 mil citações nos artigos que compõem a amostra. Williamson demonstra-se como um dos pilares na discussão sobre a TCT, na qual suas obras recebem destaque e prestígio no meio acadêmico (Rindfleisch, 2020).

O alto número de citações do artigo "The nature of the firm " não surpreende, pois é um clássico da literatura sobre o tema e demonstra sua pertinência e utilização ao passar do tempo (Rindfleisch, 2020). A sustentação teórica introduzida por Coase perpassa as décadas, ultrapassando 80 anos da publicação de sua obra (Shastitko \& Menard, 2017). Mesmo com a evolução temporal, a contribuição de Coase continua pertinente no meio acadêmico e prático acerca da TCT (Rindfleisch, 2020).

As obras de Williamson $(1975,1985)$ e Barney (1991) figuram também entre os documentos mais citados no Strategic Management Journal no período de 1980-2020 (Ramos-Rodríguez \& RuízNavarro (2004). Deste modo, a pertinência dos estudos acerca da TCT no Strategic Management Journal pode ser corroborada com os achados da Tabela 1, no qual o periódico em questão é o que possui maior número de publicações e é o mais citado.

Ao perpassar a análise das principais obras, visou-se evidenciar os principais países. A Tabela 4 expõe os 10 países mais representativos tanto em relação à frequência das publicações quanto as 
citações, ambas apresentadas com seus respectivos países. Nota-se, a partir da Tabela 4, que há predomínio de autores oriundos dos Estados Unidos.

Tabela 4 - Principais países

\begin{tabular}{c|c|c|c}
\hline \multicolumn{2}{c|}{ Publicações } & \multicolumn{2}{c}{ Citações } \\
\hline País & Frequência & País & Citações \\
\hline Estados Unidos & 5.608 & Reino Unido & 21.410 \\
\hline Reino Unido & 1.516 & Holanda & 9.293 \\
\hline China & 1.407 & China & 9.097 \\
\hline Alemanha & 879 & Canadá & 8.269 \\
\hline Austrália & 694 & Alemanha & 6.626 \\
\hline França & 689 & França & 6.410 \\
\hline Canadá & 684 & Austrália & 6.342 \\
\hline Holanda & 624 & Espanha & 4.690 \\
\hline Espanha & 473 & Itália & 3.578 \\
\hline Taiwan & 466 & &
\end{tabular}

Fonte: Elaborado pelos autores com base nos dados da pesquisa.

Ainda a respeito da internacionalização das publicações, a partir dos dados da Figura 3, observase também publicações de autores tanto de país único (Single Country Publications - SCP) como uma junção de autores de diversos países (Multiple Country Publications - MCP).

Figura 3 - Países de origem da autoria dos artigos

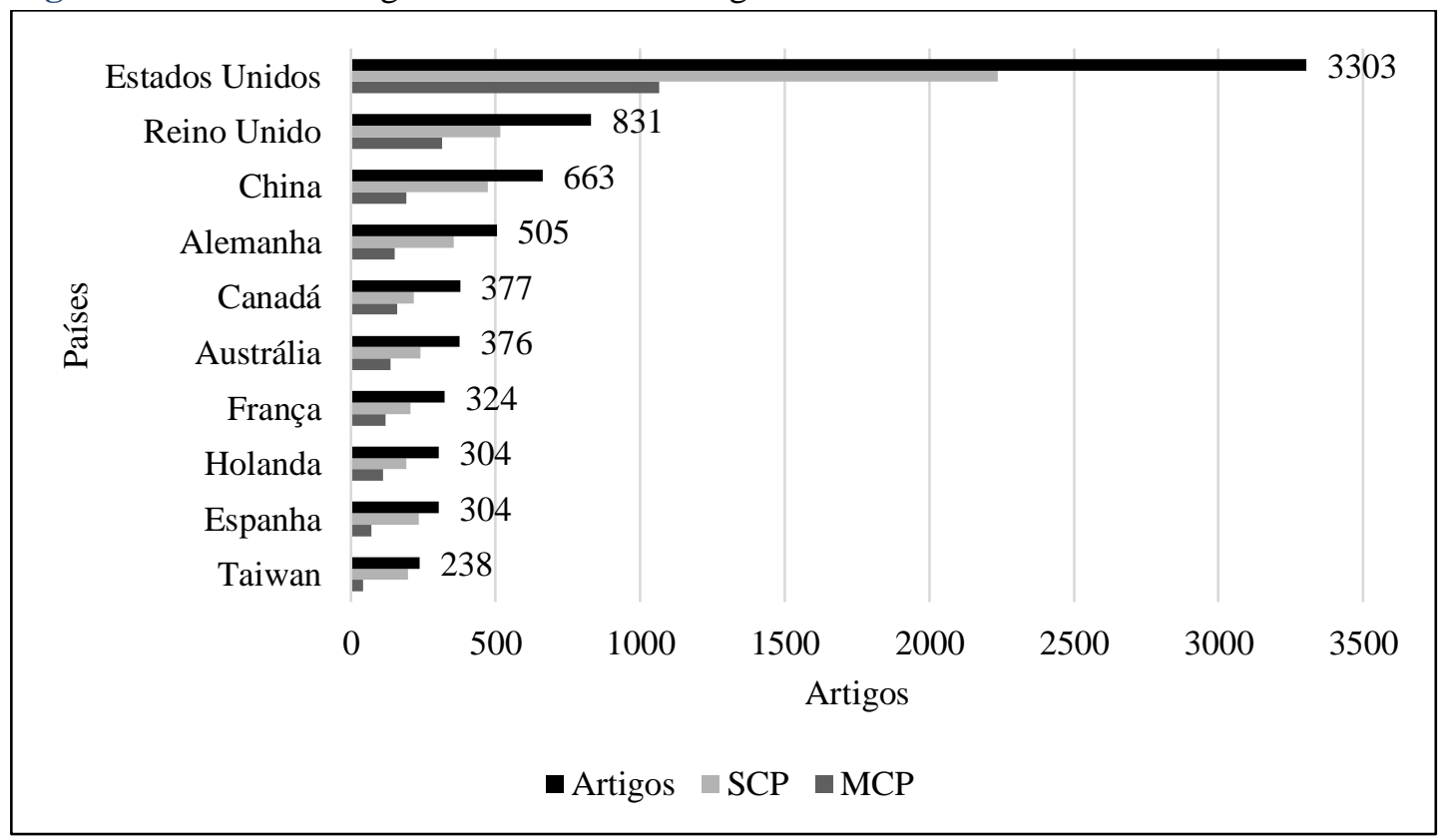

Fonte: Elaborado pelos autores com base nos dados da pesquisa. 
Frare, A. B., Horz, V., Fernandes, C. M. G., Gomes, D. G., \& Souza, M. A. (2020, July/Sept.). Teoria dos custos de transação: análise bibliométrica e sociométrica da literatura científica de 1945 a 2018

Por meio da visualização da Figura 3, têm-se os 10 países mais representativos no que concerne as publicações a respeito da TCT. Neste sentido, cabe aos Estados Unidos o maior número de publicações realizadas dentro de um intervalo temporal de 73 anos, ou seja, de 1945 a 2018 (período da análise deste estudo). Desse modo, infere-se que há uma tendência de que países mais desenvolvidos economicamente externem, por meio da ciência, a relevância em trazer à tona fatores que dizem respeito a melhorias de eficiência organizacional, possibilitando mitigar, respectivamente, tanto as incertezas como os custos incorridos (Haaskjold et al., 2019). Para Li, Ardidi e Wang (2015), a eficiência organizacional atrelada aos fatores determinantes dos custos de transação, como, por exemplo, questões envolvendo expectativas de pessoas, andamento de processos, além de problemas inerentes a contratos e contratações sinalizam que a inter-relação existente dos indivíduos com os fatores ambientais da organização dependem de uma estrutura capaz de planejar, gerenciar, executar e monitorar os custos de transação.

Ao tangenciar a existência das publicações científicas, tanto de autoria de país único quanto na relação de autores de distintos países, identifica-se que dentre os países citados (10) há uma percepção de acréscimo no número de autores que trabalham em conjunto e pertencentes a vários países. Tal constatação corrobora com os achados de Peixe et al. (2016), cujos pesquisadores buscaram pela realização de estudos científicos a partir da formação e equipes.

Os dados da Figura 4 mostram a presença de redes de colaboração entre autores. Tal visualização possibilita a percepção global da localização de regiões e países de maior representatividade no desenvolvimento de estudos sobre a TCT, bem como a percepção sobre países nos quais as pesquisas em torno desta teoria ainda são incipientes.

Figura 4 - Mapa da rede de colaboração dos autores

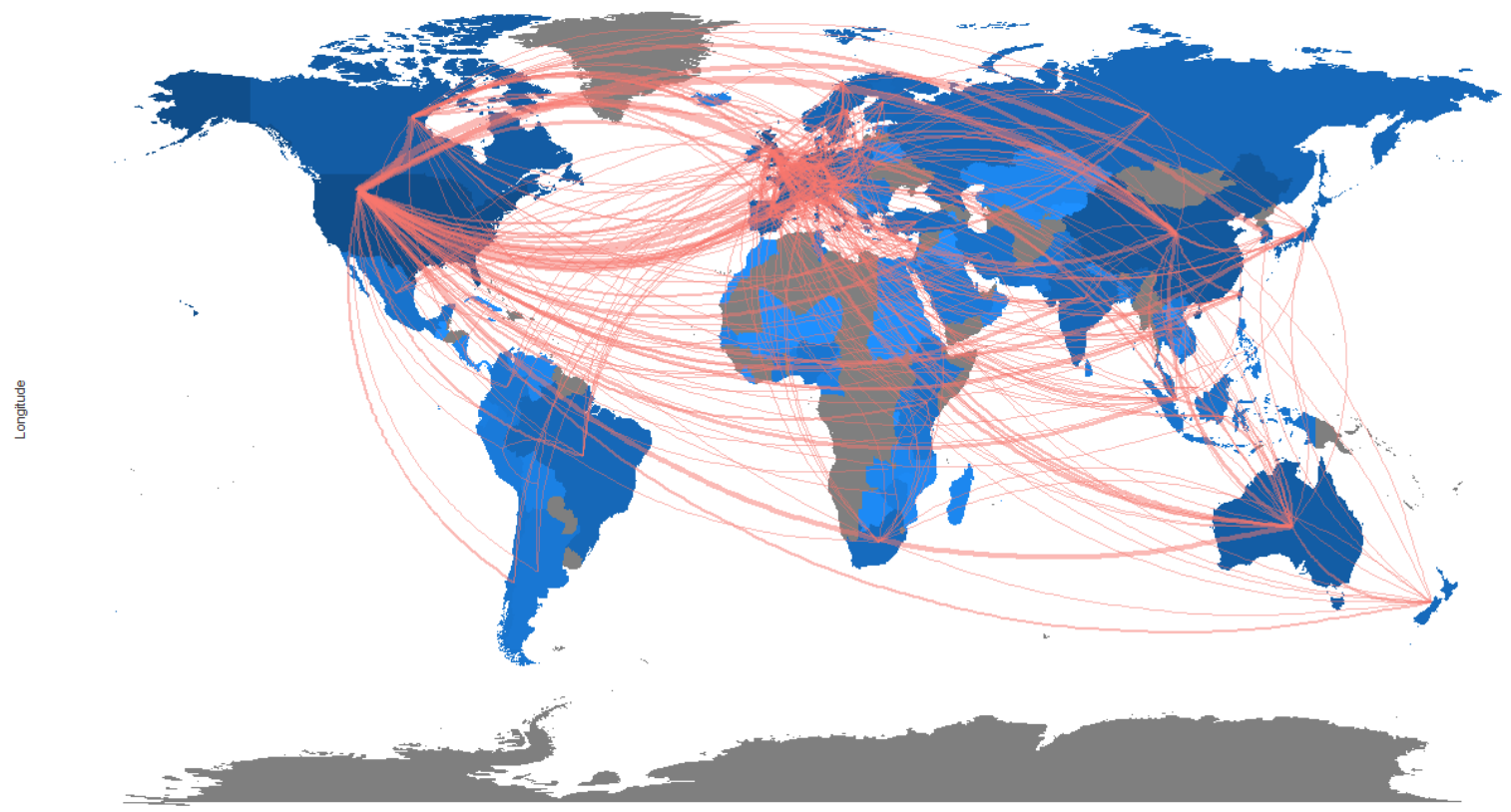

Fonte: Elaborado pelos autores com base nos dados da pesquisa tratados no package bibliometrix. 
Por intermédio da Figura 4, ratifica-se que alguns países, em especial os Estados Unidos, possuem representatividade expressiva com relação as redes de colaboração entre autores. Nesta perspectiva, pode-se perceber a intensidade de networking, principalmente entre os Estados Unidos e os países do continente Europeu. Além disso, tem-se que, até o ano de 2018, os pesquisadores brasileiros realizaram poucos estudos com parcerias internacionais no que tange a pesquisas que abarquem a TCT.

Salienta-se que as pesquisas se concentravam em estudos bibliométricos, como foi o caso dos trabalhos desenvolvidos por Arruda et al. (2013), Ferreira et al. (2014), Peixe et al. (2016), Bezerra et al. (2017) e Foscaches e Saes (2017). Tais verificações possibilitam a inferência de oportunidades no campo científico que possam tanto externar os vieses que circundam a TCT quanto possibilitar a viabilidade de estudos de caráter teórico e/ou empírico.

Outro elemento de análise objetiva identificar o encadeamento de termos e ideias que estejam relacionadas à TCT. Este é apresentado na Figura 5, elaborada a partir da nuvem de palavras (palavraschave plus e palavras-chave dos autores). A predominância de termos associados legitima a presença da teoria em suas respectivas pesquisas.

Figura 5 - Nuvens de palavras

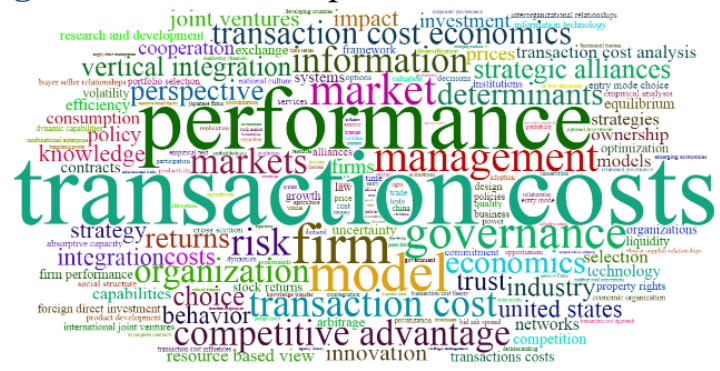

Palavras-Chave Plus

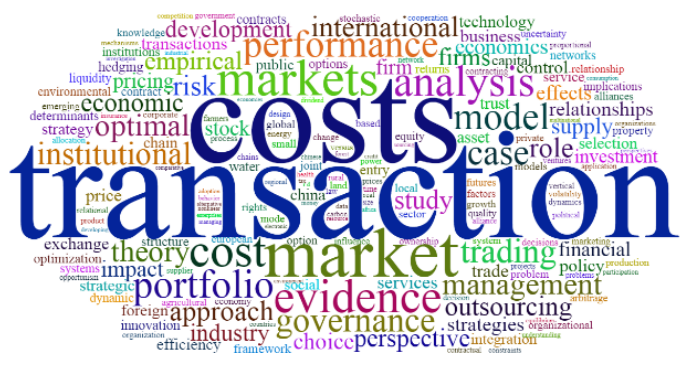

Palavras-chave dos Títulos

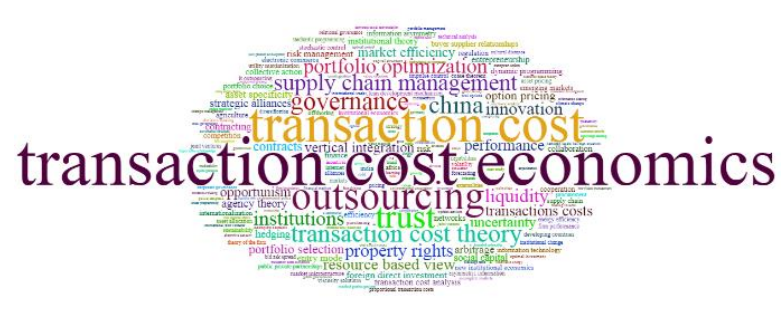

Palavras-Chave dos Autores

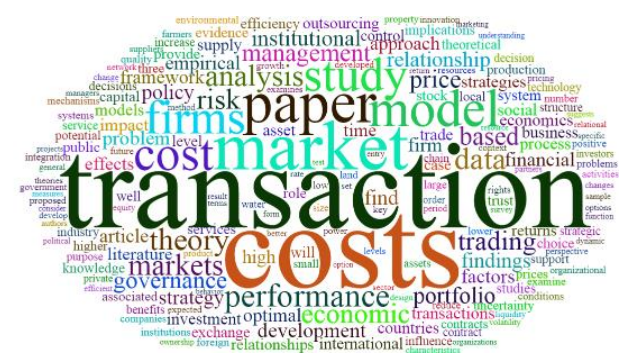

Palavras-chave dos Resumos

Fonte: Elaborado pelos autores com base nos dados da pesquisa.

A partir da Figura 5, demonstra-se que as nuvens de palavras expostas trazem como termo principal os custos de transação. Tal termo, inicialmente representado pelas palavras-chave plus, mostram que houve a citação do termo custos de transação nos títulos e indicam que tal termo foi 
empregado no decorrer dos estudos por meio de algumas palavras que tivessem similaridades quanto ao núcleo de sentido (Zhang et al., 2016).

Assim, tem-se como palavras associadas a custos de transação: "firma", "modelo", "risco", "mercado", "vantagem competitiva", etc. Conceitos como "mercado" e "firma" são os alicerces da discussão de Coase e ainda se demonstram pertinentes na discussão da TCT (Rindfleisch, 2020). A "vantagem competitiva" entoa em discussões como as de recursos das firmas (Barney, 1991), que figura entre os 10 artigos mais citados (Tabela 3). Por sua vez, a palavra "modelo" denota a aplicação de algum framework ou método para estudo de determinado aspecto relacionado a TCT, como em Klein, Frazier e Roth (1990), que investigaram um modelo de análise de custos de transação da integração de canais no mercado internacional.

Para Garfield (1990), as palavras-chave plus ou keywords plus representam a inclusão de termos adicionais que possam recuperar e/ou maximizar a representatividade do tema central do estudo. Com relação à nuvem de palavras referente às palavras-chave dos autores, Zhang et al. (2016) mencionam que estas representam uma listagem de termos que, na visão dos autores, corresponde a maneira mais pertinente de demonstrar o conteúdo que se deseja exprimir.

Em relação às palavras-chave dos títulos, infere-se a possibilidade de retratar, conforme Serra e Ferreira (2014), os termos que irão identificar o que será trabalhado no transcorrer do artigo. Para os autores, as palavras referenciadas nos títulos indicam qual "história" será contada. Por fim, ainda de acordo com Serra e Ferreira (2014), as palavras-chave presentes nos resumos aludem que este não é somente o primeiro contato que os leitores têm com o artigo, mas também a parte mais lida. Neste sentido, cabe ao pesquisador demonstrar no resumo os principais aspectos que permeiam o estudo e, por consequência, o termo que consta no cerne da pesquisa.

Assim, as palavras-chave, nas suas diversas dimensões aqui analisadas, mostram consistência com o tema da TCT, já inicialmente consideradas a partir dos trabalhos seminais de Williamson (Zhang et al., 2006). Além disso, devido ao seu arcabouço amplo, pode sinalizar a possibilidade de novas proposições articuladas a TCT, como, por exemplo, as relações existentes entre custos de transação e direitos de propriedade, com o intento de buscar subsídios que reduzem custos, tanto de forma horizontal, quanto vertical no ambiente organizacional (TCM) (Barzel, 2002; Zylbersztajn, 2018). Sob outra lente, os custos de transação podem ser minimizados a partir de questões que envolvam recursos estratégicos, como por meio da gestão dos ativos físicos e das partes interessadas (VBR) (Kellermanns et al., 2018; Santos et al., 2017).

Adiciona-se, ainda, que a rede de colaboração explora as redes de coautoria entre autores, evidenciando os autores que têm destaque por apresentar um número grande de laços (ligações) com outros autores devido à quantidade de trabalhos publicados em conjunto (Otte \& Rousseau, 2002). Neste caso, o laço representa a colaboração entre autores dos trabalhos publicados, conforme a Figura 6. 
Figura 6 - Rede de colaboração

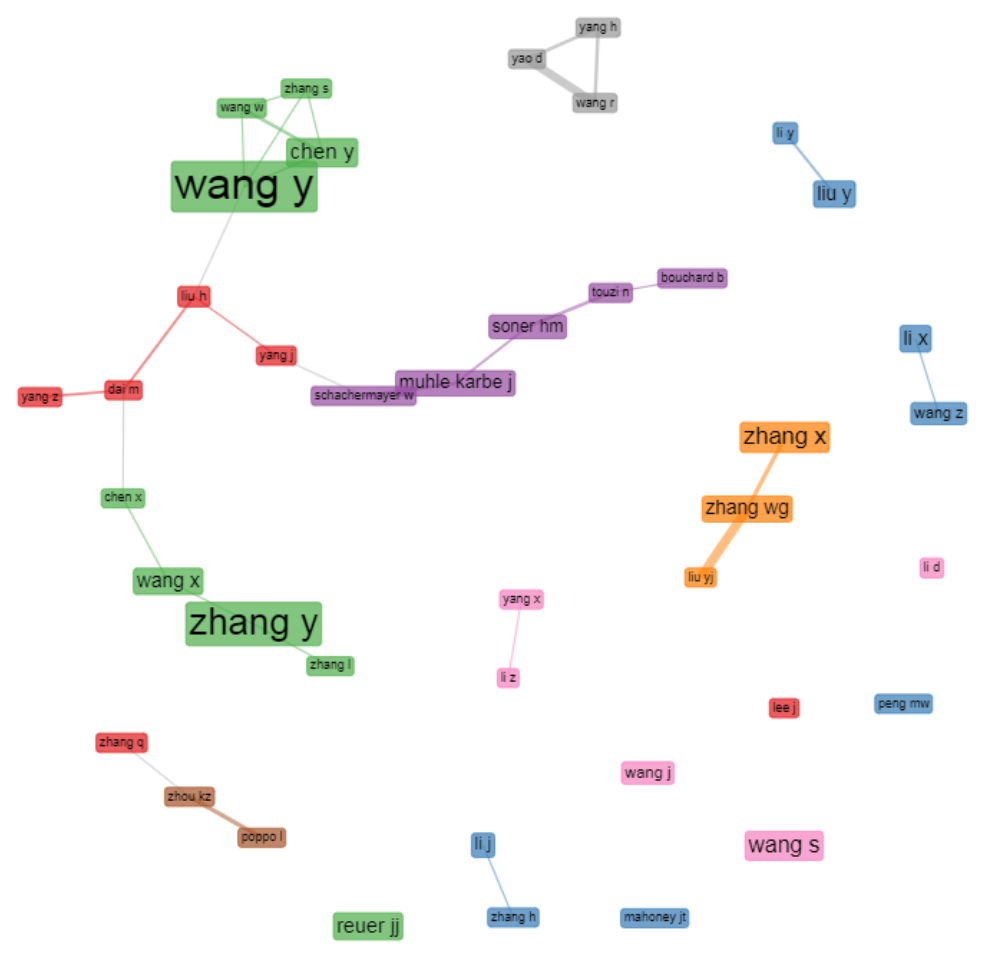

Fonte: Elaborado pelos autores com base nos dados da pesquisa tratados no package bibliometrix.

A Figura 6 mostra as redes de colaborações, em que se destacam Zhang Y. e Wang Y. como autores que concentram centros de pesquisas estruturados em formatos de rede nos quais existe a cooperação entre os autores-pesquisadores. Semelhante ao estudo de Pillania e Fetscherin (2009), observa-se o papel das redes de colaboração dos autores para identificar os paradigmas atuais e contribuir para o desenvolvimento da teoria.

A análise de cocitação baseia-se em examinar com que frequência um determinado par de obras é citado por outros trabalhos (Acedo \& Casillas, 2005). De fato, são os trabalhos mais frequentemente citados que refletem alguma proximidade intelectual, uma vez que provavelmente estão lidando com o mesmo tema. A Figura 7 apresenta a rede de cocitações. 
Figura 7 - Rede de cocitação

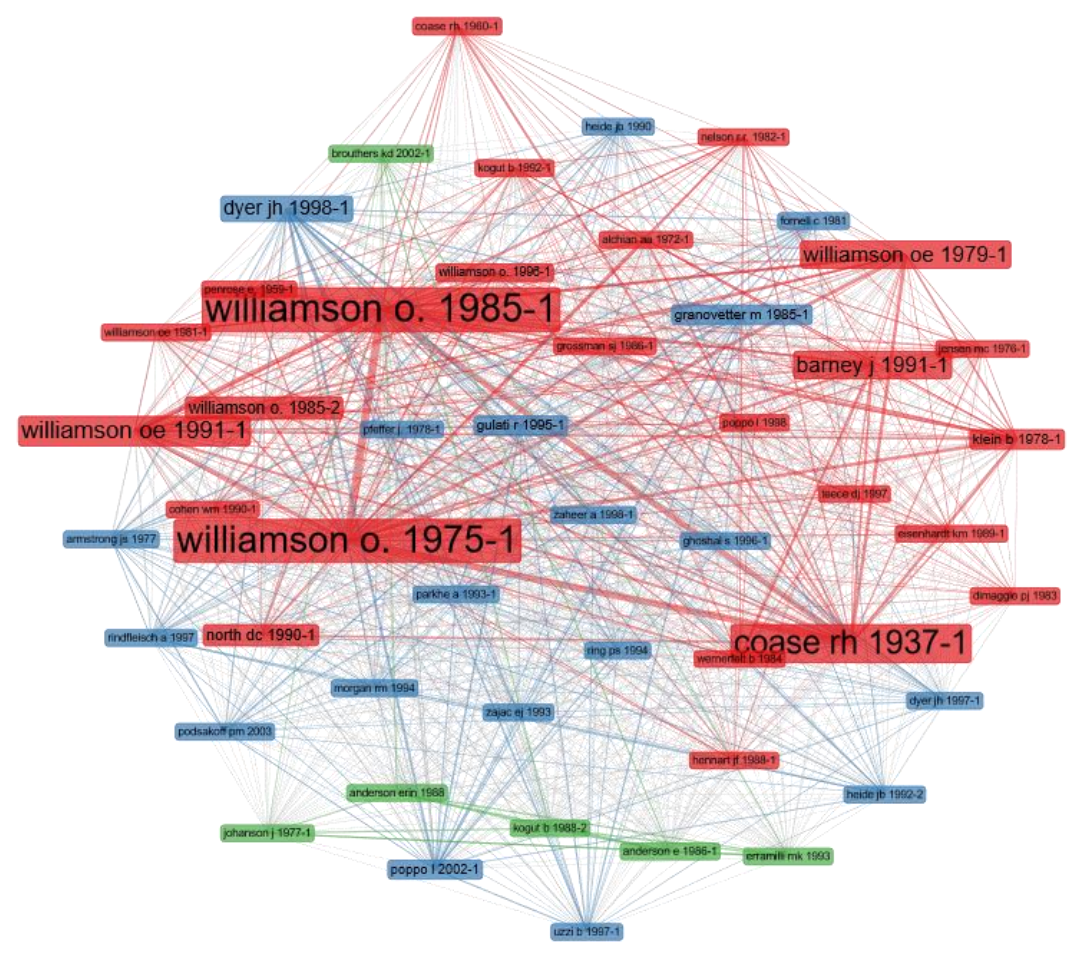

Fonte: Elaborado pelos autores com base nos dados da pesquisa tratados no package bibliometrix.

Por meio da visualização gráfica da Figura 7, pode-se averiguar a cocitação entre as obras seminais da TCT, como as de Williamson, Coase, Dyer, North e Barney. Este achado evidencia a rede de cocitação elucidada mediante a abordagem da literatura clássica de TCT, uma vez que contempla os autores precursores e que recebem maior atenção na temática em questão. A rede de cocitação não surpreende, pois Coase é considerado o fundador da TCT (Benkler, 2006; Williamson 1985) e Williamson foi um dos principais teoristas na construção da TCT (Rindfleisch, 2020).

\section{Considerações finais}

A presente investigação teve por objetivo analisar as características das publicações científicas na temática da Teoria dos Custos de Transação. Para tanto, após a inclusão de critérios para a seleção do portfólio de artigos na base de dados Web of Science, 9.907 artigos foram identificados e analisados com o auxílio do package bibliometrix nos softwares R e RStudio. A amostra de artigos contempla o período de 1945 até 2018, mostrando um constante crescimento, principalmente após a década de 1990. A partir dos artigos selecionados, foi possível identificar os periódicos que mais publicaram sobre o tema e os autores pioneiros e mais profícuos.

Com relação aos países de origem de autoria dos artigos, há um predomínio por parte dos pesquisadores dos Estados Unidos, cabendo também a este país a primazia com relação a redes de colaboração entre autores, ou seja, a busca por parcerias com pesquisadores de distintos países. Além 
disso, com relação a exposição das quatro nuvens de palavras-chave, tem-se que os autores buscam por enfatizar termos discutidos nos artigos, com predominância do termo "custos de transação" que se encontra explícito em todos os conjuntos de palavras.

As expressivas redes de colaboração e de cocitações são evidenciadas, mostrando as conexões para desenvolvimento conjunto (ou isoladas, como no caso de Williamson), e representam parcerias e esforços para maiores inserções sobre o tema TCT. Como resultante, a temática TCT passa a ser mais estudada e discutida, facilitando a identificação de paradigmas atuais e contribuindo para o desenvolvimento da teoria.

A investigação contribui de forma teórica ao complementar a discussão acerca da TCT, evidenciada em outros artigos com caráter revisionais. Tal contribuição se dá de forma ao explicitar as características das publicações sobre a TCT, evidenciando um amplo panorama de variáveis e informações obtidas a partir de uma amostra com quase dez mil artigos. Desta forma, surge a implicação de entrelaçar as circunstâncias e fenômenos socialmente construídos e institucionalizados no âmbito da TCT, seja por conexões e laços intelectuais, sociais, paradigmáticos ou culturais.

A partir dos achados, implicações para a prática também podem ser elucidadas. Primeiramente, pesquisadores podem se alicerçar neste estudo para compreender a dinâmica, particularidades, estado da arte e tendências de tal teoria. Segundo, pelo contexto das organizações, o estudo propicia a identificação da evolução e construção de aspectos pertinentes à teoria, o que pode facilitar aos interessados o entendimento da origem, conceitos e aplicação, assim podendo instigar uma nova visão singular nos processos, métodos e mecanismos gerenciais.

Sob a ótica de um cenário competitivo, a escolha por melhores arranjos contratuais e a minimização de assimetria da informação podem auxiliar na eficiência das transações comerciais, de forma a se apresentar como fator decisivo de competitividade para as organizações. Conhecer as discussões sobre a TCT, como a assimetria informacional, arranjos contratuais, racionalidade limitada e outros fatores, juntamente com demais temas investigados neste contexto, pode auxiliar aos gestores a emergirem em novos insights e olhares sobre os custos de transação da firma, o que pode promover uma gestão mais eficaz e consequentemente fomentar a vantagem competitiva.

O estudo possui algumas limitações, como utilizar uma única base de dados (Web of Science), não utilizar siglas nos critérios de seleção da amostra, como, por exemplo TCT (Transaction Costs Theory), assim como explorar as discussões de forma global, sem investigar profundamente cada artigo, as abordagens, métodos e técnicas utilizadas. A partir das limitações expostas, surgem oportunidades de novas pesquisas, justamente para suprir as lacunas apontadas.

A partir da discussão dos resultados obtidos, novos estudos podem explorar de maneira mais profunda algumas das tendências evidenciadas. Desta forma, a agenda de pesquisas futuras pode considerar diversos aspectos elucidados nessa pesquisa. Primeiramente, torna-se interessante explorar quais fatores contribuem para o Strategic Management Journal ser o periódico com maior número de publicações e o mais referenciado. Nesta perspectiva, pesquisas revisionais sobre a TCT poderiam focar 
este periódico em questão, abarcando os principais estudos sobre o tema e o papel destes na disseminação e construção da teoria.

Segundo, compreender o avanço do conhecimento sobre TCT pelas pesquisas dos autores mais profícuos pode ser um caminho interessante. Deste modo, novas pesquisas podem explorar os estudos dos dez autores com maior proficuidade para entender possíveis similaridades e particularidades de conceitos, abordagens, métodos e perspectivas utilizadas por cada autor. Análises qualitativas dos estudos desses autores poderiam auxiliar na possível descoberta de paradigmas e empregabilidade da TCT nas pesquisas em questão, de forma a elucidar os desdobramentos da aplicação da TCT sob a ótica dos autores prolíferos.

Terceiro, existe a possibilidade de comparar o viés e abordagem das pesquisas entre Estados Unidos, China e países europeus, que figuram entre os países com mais publicações e mais citados. Neste contexto, torna-se oportuno explorar as características e possíveis fenômenos na construção das redes de colaboração internacionais. Sob a lente supracitada, novas investigações podem permear a construção da literatura sobre TCT de um determinado país e, neste intento, entrelaçar com as redes internacionais de coautoria que tal país apresenta.

Quarto, sugere-se um novo olhar para os principais termos dispostos nas palavras-chave. Assim, estudos futuros podem categorizar os termos mais recorrentes e explorá-los por meio de análise de conteúdo ou demais técnicas similares. Mediante essa possibilidade, as múltiplas facetas da aplicabilidade da TCT podem ser organizadas. Desta forma, as linhas de pensamento e discussão poderiam ser sistematizadas conforme os próprios vieses, áreas e temas que se alicerçam na TCT.

Quinto, recomenda-se investigar a rede de colaboração, de maneira a explorar as relações constituídas por determinados autores e/ou grupos de pesquisa. Essa perspectiva pode auxiliar no entendimento do avanço do conhecimento por meio das linhas de pensamento e características de cada rede em específico. Ademais, explorar possíveis conexões entre as redes de países diferentes pode trazer achados pertinentes, uma vez que demonstra a proximidade das discussões de TCT entre pesquisadores dos países em questão.

Sexto, surge a oportunidade de investigar a composição das redes de cocitação de acordo com temas ou vieses mais específicos no contexto da TCT. Em outras palavras, por meio da compreensão das cocitações podem surgir evidências de clusters de obras citadas em detrimento do tema em que se está sendo explorado. Por fim, novas pesquisas podem promover diferentes olhares sobre a produção científica de TCT, seja por diferentes métodos para seleção do portfólio de documentos, outras bases de dados, novas abordagens e técnicas de análise, além de distintas delimitações revisionais e metodológicas.

\section{Referências}

Acedo, F, J, \& Casillas, J, C. (2005). Current paradigms in the international management field: An author co-citation analysis. International Business Review, 14(5), 619-639. 
Aguilera, R. V., Crespí-Cladera, R., Infantes, P. M., \& Pascual-Fuster, B. (2020). Business groups and internationalization: Effective identification and future agenda. Journal of World Business, 55(4), 117.

Allen, D. W. (1999). Transaction costs. Encyclopedia of Law and Economics.

Andrade, P. L., Barbosa, D. M. S., \& Santos. T. A. (2015). Estratégia e custos de transação: uma revisão sistemática. Anais do Encontro Nacional de Engenharia da Produção. Fortaleza, CE: ABEPRO.

Aria, M., \& Cuccurullo, C. (2017). bibliometrix: An R-tool for comprehensive science mapping analysis. Journal of Informetrics, 11(4), 959-975.

Arrow, K. J. (1969). The organization of economic activity: issues pertinent to the choice of market versus nonmarket allocation. The analysis and evaluation of public expenditure: the PPB system, 1, 500-518.

Arruda, A. G., Benevides, G., Farina, M. C., \& Faria, A. C. (2013). Teoria dos Custos de Transação (TCT): Análises bibliométrica e sociométrica nos Enanpad de 1997 a 2010. Revista de Administração da UNIMEP, 11(2), 174-199.

Bardin, L. (2016). Análise de Conteúdo. Lisboa, Portugal; Edições 70.

Barney, J. (1991). Firm resources and sustained competitive advantage. Journal of Management, 17(1), 99-120.

Barzel, Y. (2002). Organizational forms and measurement costs. Journal of Institutional and Theoretical Economics (JITE)/Zeitschrift für die gesamte Staatswissenschaft, 357-373.

Benkler, Y. (2006). The wealth of networks. New Haven: Yale University Press.

Bezerra, G. J., Schultz, G., Schinaider, A. D., \& Schinaider, A. D. (2017). Custos de Transação no agronegócio: Uma revisão sistemática das publicações internacionais. Espacios, 38(38), 16-29.

Bužavaite, M., Ščeulovs, D., \& Korsakienė, R. (2019). Theoretical approach to the internationalization of SMEs: Future research prospects based on bibliometric analysis. Entrepreneurship Sustain, 6(3), 1497-1511.

Coase, R. H. (1937). The nature of the firm. Economica, 4(16), 386-405.

Coase R. H. (1960). The problem of Social Cost. The Journal of Law and Economics, 3(oct), 1-44.

Colepicolo, E. (2014). Buscando informação científica de qualidade para pesquisa em Psicologia. Estudos Interdisciplinares em Psicologia, 5(2), 133-142.

Dyer, J. H., \& Singh, H. (1998). The relational view: Cooperative strategy and sources of interorganizational competitive advantage. Academy of management review, 23(4), 660-679.

Earl, P. E., \& Potts, J. (2011). A nobel prize for governance and institutions: Oliver williamson and elinor ostrom. Review of Political Economy, 23(1), 1-24.

Ferreira, M. P., Pinto, C. F., \& Serra, F. R. (2014). The transaction costs theory in international business research: a bibliometric study over three decades. Scientometrics, 98, 1899-1922. 
Ferreira, M. P., Storopoli, J. E., \& Serra, F. R. (2014). Two decades of research on strategic alliances: analysis of citations, co-citations and themes researched. Revista de Administração Contemporânea, 18(special), 109-133.

Foscaches, C., \& Saes, (2017). M. S. M. Economia dos Custos de Transação e Teoria da Identidade: Um estudo bibliométrico. Desafio Online, 5(3), 351-365.

Fox, G. (2007). The real Coase theorems. Cato Journal, 27(3), 373.

Garfield, E. (1990). Keywords plus: ISI's breakthrough retrieval method. Part I. Expanding your searching power on current contents on diskette . Current Contents, 13(32), 295-299.

Haaskjold, H., Andersen, B., Lædre, O., \& Aarseth, W. (2019). Factors affecting transaction costs and collaboration in projects. International Journal of Managing Projects in Business, 13(1), 197-230.

Habimana, O. (2015). From Coase to Williamson: Evolution, Formalization and Empirics of Transaction Cost Economics. Journal of Social Economics, 3(1), 36-42.

Kellermanns, F., Walter, J., Crook, T. R., Kemmerer, B., \& Narayanan, V. (2016). The resource-based view in entrepreneurship: A content-analytical comparison of researchers' and entrepreneurs' views. Journal of Small Business Management, 54(1), 26-48.

Klein, S., Frazier, G. L., \& Roth, V. J. (1990). A transaction cost analysis model of channel integration in international markets. Journal of Marketing Research, 27(2), 196-208.

Li, H., Arditi, D., \& Wang, Z. (2015). Determinants of transaction costs in construction projects. Journal of Civil Engineering and Management, 21(5), 548-558.

Madhok, A. (2002). Reassessing the fundamentals and beyond: Ronald Coase, the transaction cost and resource-based theories of the firm and the institutional structure of production. Strategic Management Journal, 23(6), 535-550.

Maranho, F. S., Abib, G., \& Fonseca, M. W. (2013). As pesquisas em estratégia no Brasil sob a perspectiva da Teoria dos Custos de Transação. Anais do Encontro de Estudos em Estratégia. Bento Gonçalves, RS: 3Es.

Martinez, A. L. (1998). Agency Theory na Pesquisa Contábil. Anais do Encontro Nacional dos Programas de Pós-Graduação em Administração - ENANPAD. Foz do Iguaçú, PR: ANPAD.

Martins, R., Serra, F., Leite, A., \& Ferreira, M. P. (2010). Transactions Cost Theory influence in strategy research: A review through a bibliometric study in leading journals. Journal of Strategic Management Education, 6(3), 1-29.

Martins, G. A., \& Theóphilo, C. R. (2009). Metodologia da investigação científica para Ciências Sociais Aplicadas. São Paulo: Atlas.

Nerur, S. P., Rasheed, A. A., \& Natarajan, V. (2008). The intellectual structure of the strategic management field: An author co-citation analysis. Strategic Management Journal, 29(3), 319-336.

North, D. C. (1990). Institutions, institutional change and economic performance. Cambridge: Cambridge University Press.

North, D. C. (1994). Economic performance through time. The American economic review, 84(3), 359-368. 
Otte, E., \& Rousseau R. (2002). Social network analysis: a powerful strategy, also for the information sciences. Journal of Information Science, 28(6), 441-453.

Peixe, A. M. M., Rosa Filho, C., Passos, G. A., Formiga, M. V., \& Peixe, B. C. S. (2016). Custos de transação aplicados no setor público e privado: uma análise bibliométrica das edições do Congresso Brasileiro de Custos e USP International Conference in Accounting. Anais do Congresso Brasileiro de Custos. Porto de Galinhas - PE: CBC.

Pillania, R., \& Fetscherin, M. (2009). The state of research on multinationals and emerging markets. Multinational Business Review, 17(2), 5-15.

Ramos-Rodríguez, A. R., \& Ruíz-Navarro, J. (2004). Changes in the intellectual structure of strategic management research: A bibliometric study of the Strategic Management Journal, 1980-2000. Strategic management journal, 25(10), 981-1004.

Rindfleisch, A. (2020). Transaction cost theory: past, present and future. Academy of Marketing Science, 10, 85-97.

Sánchez-Riofrío, A. M., Guerras-Martín, L. Á., \& Forcadell, F. J. (2015). Business portfolio restructuring: a comprehensive bibliometric review. Scientometrics, 102(3), 1921-1950.

Santos, N. M., Ferraz, I. N., Falqueto, J. M. Z., \& Verga, E. (2017). The Transaction Cost Theory in Strategy Research in Brazil. Revista Ibero Americana de Estratégia, 16(2), 04-18.

Sarto, V. H. R., \& Almeida, L. T. (2015). A teoria de custos de transação: uma análise a partir das críticas evolucionistas. Revista Iniciativa Econômica, 2(1), 1-25.

Serra, F. A. R., \& Ferreira, M. A. S. P. V. (2014). O título, resumo e palavras-chave dos artigos. Revista Ibero Americana de Estratégia, 13(4), 1-7.

Serra, F., Ferreira, M., Guerrazzi, L., \& Scaciotta, V. (2018). Doing Bibliometric Reviews for the Iberoamerican Journal of Strategic Management. Iberoamerican Journal of Strategic Management (IJSM), 17(3), 01-16.

Shastitko, A., \& Ménard, C. (2017). Discrete institutional alternatives: Theoretical and policy issues (Celebrating the 80th anniversary of Ronald Coase's "Nature of the Firm"). Russian Journal of Economics, 3(2), 200-220.

Thielmann, R. (2013). A Teoria dos Custos de Transação e as Estruturas de Governança: uma Análise do Caso do Setor de Suinocultura no Vale do Rio Piranga - Mg. Anais do Simpósio de Excelência em Gestão e Tecnologia.

Williamson O. E. (1975). Markets and Hierarchies: Analysis and Antitrust Implications: A Study in the Economics of Internal Organization. New York: Free Press.

Williamson O. E. (1979). Transaction-Cost Economics: The Governance of Contractual Relations. The Journal of Law and Economics, 22(2), 233-261.

Williamson, O. E. (1981). The economics of organization: the transaction cost approach. The American Journal of Sociology, 87(3), 548-577.

Williamson, O. E. (1985). The economic institutions of capitalism. New York: Free Press.

Williamson O. E. (1991). Comparative Economic Organization: The Analysis of Discrete Structural Alternatives. Administrative Science Quarterly, 36(2), 269-296. 
Williamson, O. E. (1994). The institutions and governance of economic development and reform. The World Bank Economic Review, 8(1), 171-197.

Williamson, O. E. (1998). Transaction cost economics: how it works; where it is headed. De Economist, 146(1), 23-58.

Zhang, J., Yu, Q., Zheng, F., Long, C., Lu, Z., \& Duan, Z. (2016). Comparing keywords plus of WOS and author keywords: A case study of patient adherence research. Journal of the Association for Information Science and Technology, 67(4), 967-972.

Zylbersztajn, D. (2018). Measurement costs and governance: bridging perspectives of transaction cost economics. Caderno de Administração, 26(1), 1-19. 